América sin Nombre, n. ${ }^{\circ} 24$ (2020): 23-33

DOI 10.14198/AMESN.2020.24-2.02

ISSN: 1577.3442 / eISSN: 1989-9831

Fecha de recepción: 18/02/2019

Fecha de aceptación: 22/02/2019
Modo de citación de este artículo:

Gallego Cuiñas, Ana y Oteros Tapia, María José. «El camino de Ida de Ricardo Piglia: una novela de campus feminista». La nueva novela latinoamericana sin limites. Lise Segas y Félix Terrones (coordinadores). América sin Nombre, 24 (2019): 23-33, DOI: 10.14198/AMESN.2020.24-2.02

Link para este artículo: http://dx.doi.org/10.14198/AMESN.2020.24-2.02

\title{
El camino de Ida de Ricardo Piglia: una novela de campus feminista
}

\author{
El camino de Ida by Ricardo Piglia: a feminist campus novel
}

\author{
Ana Gallego Cuiñas* y María José Oteros Tapia** \\ Universidad de Granada
}

\section{Resumen}

La crítica hispanista ha analizado las representaciones femeninas de la producción literaria de Ricardo Piglia como fruto de una tradición conservadora, sin embargo en su última novela, El camino de Ida (2013) — que también puede ser leída como una novela de campus-, el autor argentino viene a revertir esta concepción tradicional de lo femenino latente en su narrativa anterior, en aras del delineamiento de un marco de legibilidad feminista. Con este horizonte, nuestro trabajo tiene como objeto evidenciar la convergencia dada entre novela de campus y feminismo en El camino de Ida de Ricardo Piglia para proponer la hipótesis de que esta publicación se constituye como una de las primeras novelas de campus feministas en Argentina.

Palabras clave: Ricardo Piglia, narrativa argentina, novela de campus, sujeto femenino, feminismo.

\section{Abstract}

Althoug the critic has attended to observe the female representations of Ricardo Piglia's literary production as a product of conservative tradition, with his last novel, El camino de Ida (2013) — which on the other hand, can be read as a campus novel一, the Argentine writer comes to revert this suppressed traditional conception of the female in his previous fiction, for the sake of a frame of feminist legibility. Therefore, our paper aims to highlight the existing convergence between novel

* Profesora titular del Departamento de Literatura Española de la Universidad de Granada. Doctora en Filología Hispánica y licenciada en Antropología Social y Cultural por la Universidad de Granada, ha sido contratada del programa «Ramón y Cajal» e investigadora visitante en la Universidad de California Los Ángeles, Princeton, Paris-Sorbonne, Buenos Aires y Yale. Numerosos libros, ensayos y artículos han aparecido en editoriales y revistas de reconocido prestigio internacional sobre temas dominicanos, narrativa rioplatense contemporánea, escritura autobiográfica (diarios y cartas), estudios transatlánticos de literatura, y acerca de la relación entre literatura y economía. Sus últimos libros son Las novelas argentinas del siglo 21. Nuevos modos de producción, circulación y recepción (2019) y Otros. Ricardo Piglia y la literatura mundial (2019). En la actualidad es la Investigadora Principal del proyecto I+D LETRAL, directora de la Unidad Científica de Excelencia Iber-Lab «Crítica, Lenguas y Culturas en Iberoamérica» y Vicedecana de Cultura e Investigación de la Facultad de Filosofía y Letras de la Universidad de Granada.

** Contratada predoctoral en la Universidad de Granada. Graduada en Filología Hispánica y doble máster en Educación y Estudios Latinoamericanos: Cultura y Gestión. En 2016 obtuvo una Beca de Colaboración en el Departamento de Literatura Española; en 2017 una Beca de Iniciación a la Investigación (grado) con la que estudió el mercado editorial en Andalucía y en 2018 una Beca de Iniciación a la Investigación (máster) centrando su tema de estudio en la narrativa de campus argentina. Actualmente, está inserta en su proyecto de tesis con el que pretende estudiar la novela de campus en el siglo Xxi a ambos lados del Atlántico. 
campus and feminism in El camino de Ida of Ricardo Piglia, which allows us to propose the hypothesis of this publication by Argentinte writer is one of the first feminist campus novel in Argentine.

Keywords: Ricardo Piglia, Argentine narrative, campus novel, female subject, feminism.

\section{Introducción}

El camino de Ida (2013), la última novela de Ricardo Piglia, ha sido objeto de estudio de varios ensayos que han ahondado en las posibilidades hermenéuticas de la obra a través de categorías como la ficción paranoica (Fernández Cobos), la exploración de la violencia anticapitalista (Dawes) o el género policial (García del Río), entre otras. Sin embargo, la crítica parece no haber atendido a la posibilidad de leer el texto como una novela de campus o más específicamente, como un policial académico.

Desde sus orígenes, el subgénero narrativo de novela de campus ha sido ampliamente abordado en el ámbito de la academia inglesa y estadounidense. Sin embargo, pocos son los estudios que existen acerca de este subgénero en el mundo hispánico (García Rodíguez, Moore-Martínez, Villamía y GilAlbarellos) y más especialmente, en la Argentina (Reati y Gómez Ocampo y Maltz), donde desde la década de los noventa estamos asistiendo a un auge incontestable de este tipo de narrativas.

Por otro lado, el estudio crítico de las representaciones femeninas en la producción pigliana ha puesto el foco en la consideración de sus personajes mujeres como fruto de una visión conservadora. No obstante, la última novela que publicó el autor argentino viene a revertir esta concepción tradicional de lo femenino latente en su narrativa anterior, en aras del delineamiento de un marco de legibilidad feminista. Con este horizonte, nuestro trabajo tiene como objetivo evidenciar la convergencia dada entre novela de campus y feminismo en El camino de Ida de Ricardo Piglia, para proponer la hipótesis de que esta publicación de Ricardo Piglia se constituye como una de las primeras novelas de campus feministas en Argentina.

\section{La novela de campus en Argentina: un subgénero narrativo en auge}

La novela de campus como subgénero narrativo cuenta con una corta trayectoria en la historia de la literatura mundial. Sus orígenes se remontan a mediados del xx en Estados Unidos e Inglaterra
(Castagnino 125), con el desplazamiento que se produce desde la experiencia del estudiante (novela de universidad) a la experiencia del profesor o/y investigador (novela de campus) como eje central de la trama. Frente a las novelas de formación que constituían las novelas de universidad, las de campus se centran en las preocupaciones y contradicciones que sufre el profesor/investigador universitario con respecto a la institución en la que trabaja. Sin embargo, la breve historia del género no ha impedido que bajo este marbete se congregue una miríada de novelas con un amplio espectro temático y formal que reconoce y pone de manifiesto un auge significativo de la novela de campus, desde fines del siglo xx hasta nuestros días.

Asimismo, encontramos otro factor que ha propiciado el cultivo de este subgénero: los escritores, principalmente latinoamericanos, ejercen cada vez más de profesores universitarios en EEUU y en América Latina, ya sea en periodos cortos o prolongados (v.g., Vargas Llosa, Carlos Fuentes, Ricardo Piglia, Martín Kohan, Lina Meruane, Alejandro Zambra, Florencia Abbate, Valeria Luiselli, Carlos Yushimito, etc.). Si el sustento profesional de los escritores del boom solía ser el periodismo, desde los ochenta ha ido ganando terreno la labor universitaria, que redunda no solo en el desarrollo de la novela de campus, sino en un acercamiento entre las lógicas de producción (ficcional) y de interpretación (crítica) que se avienen a la circulación de poéticas muy literaturizadas, que articulan un marco de legibilidad teórico orientado a un lector - universitario- especializado.

Por otro lado, la naturaleza e idiosincrasia de los sistemas universitarios de Estados Unidos y Reino Unido localizados, normalmente, en campus universitarios que posibilitan que el lugar de aprendizaje y formación se convierta a la vez en el lugar de residencia, ha devenido en nuevas formas de tratamiento y cruces de géneros con respecto al modelo inicial en espacios donde no se da la existencia de un campus académico a la manera anglosajona. Este es el caso del de la novela de campus argentina, país cuya universidad difiere mucho del modelo americano. En Argentina, al igual que en España, las instituciones académicas se entienden exclusivamente como 
lugares de formación, lo que produce que en ambos países existan una suerte de novelas que se asemejan más a las originarias del género, hasta el punto de que sus tramas se encuadran en universidades extranjeras, sobre todo en Estados Unidos (El camino de Ida) o en Inglaterra (Crimenes imperceptibles). Las diferencias políticas y estructurales de estos países posibilitan la reformulación de los modelos clásicos y la conjugación entre diferentes modelos de universidades que no hacen otra cosa que enriquecer la trama, a través de la mirada del extranjero que se inserta en un espacio que no es el propio.

A esto hay que sumar el fuerte anclaje de la tradición literaria argentina en el género policial, que ha devenido en su cruce con la novela de campus. Según Lafforgue «ningún otro género, como el policial, ha estructurado tan raigalmente el sistema de la ficción argentina a lo largo de este siglo [XX]» (11) y por tanto, no sorprende que este aparezca mezclado con otras formas estilísticas. La historia del policial argentino, ampliamente estudiada por la crítica, señala la aparición del subgénero catalogado como policial académico en el año 1975, con la publicación de «La loca y el relato del crimen» de Ricardo Piglia (Sasturain 42), cuento en el que — su ya recurrente personaje-Emilio Renzi resuelve un crimen a través de la competencia lingüística que ha adquirido en una institución universitaria.

Al relato de Piglia podrían seguirle otras obras argentinas que se enmarcarían dentro de este subgénero mixto como son: El agua electrizada (1992) de Carlos Feiling, Filosofía y Letras (1998) y La traducción (1998) de Pablo De Santis, La Cátedra (2000) de Nicolás Casullo, Crímenes imperceptibles ${ }^{1}$ (2003) de Guillermo Martínez, El ícono de Dangling (2007) de Silvia Maldonado y El camino de Ida (2013), también de Ricardo Piglia. Todas ellas, a pesar de presentar de forma variada y diferenciada el mundo académico, tienen en común la aparición de personajes universitarios que lideran investigaciones sobre crímenes y/o ámbitos académicos en los que se producen crímenes (Maltz 134).

Sin embargo, aunque el género de la novela de campus esté relacionado en gran medida con el género policial en Argentina, también existen una serie de obras que no introducen el elemento policial en su trama, acercándose más a los modelos clásicos ingleses y estadounidenses de novela de campus. Nos referimos a novelas como Los

1. Editado en España como Los crimenes de Oxford. misterios de Rosario (1994) y El congreso de literatura (1997) de César Aira, Filo (2003) de Sergio Olguín, Pegamento (2004) de Gloria Pampillo, El puñal de Dido (2007) de Carlos Balmaceda, Las teorias salvajes (2008) de Pola Oloixarac, Yo también tuve una novia bisexual (2010) de Guillermo Martínez, Cataratas (2015) de Hernán Vanoli y Plato paceño (2015) de Alfredo Griego y Bravio. De esta nómina —necesariamente incompleta- de obras que podrían incluirse también bajo el rótulo de novela de campus se observa una amplia producción a partir de la década de los noventa que llega hasta nuestros días, lo que vendría a poner de relieve la vitalidad y auge del subgénero en el continente americano.

Así Ricardo Piglia se suma con su última novela a esta expansión de la novela de campus argentina, en su forma más convencional. Por un lado, el autor de Respiración artificial ha sido profesor en Princeton University durante más de veinte ańos y por otro, es uno de los grandes cultivadores del género policial latinoamericano. De esta experiencia vital y de la estructura literaria que da la base a este subgénero, la novela de campus, surgirá El camino de Ida, que presenta a Renzi como investigador de un crimen en un campus universitario de New Jersey, y a Ida, como una intelectual feminista antisistema que aparece como reverso de Thomas Munk, trasfondo a su vez de Theodore Kaczynski, más conocido como Unabomber. La historia de este filósofo matemático, anarquista en contra de "la sociedad industrial», que en la década de los ochenta y noventa envió cartasbomba a universidades, se ha revitalizado al albur de la serie creada por Netflix en $2017^{2}$. Sin embargo, la versión que deja entrever Ricardo Piglia de la lógica paranoica del sistema universitario norteamericano y de la historia de intelectuales, graduados en Harvard que se desvían de la norma, como Unabomber, se aviene a una lectura feminista, antinormativa, que va más allá de la postura ecológica y anti-tecnológica del Kaczynski, encarnada en la protagonista que da título a la novela: Ida. Con ella, como veremos, se inaugurará en la Argentina la novela de campus feminista.

2. En 2003 salió a la luz un magnífico documental independiente del alemán Lutz Dammbeck, Das Netz, sobre Unabomber que fue traducido al inglés como The Net. The Unabomber, LSD and the Internet, al que bien pudo tener acceso Ricardo Piglia. 


\section{Las representaciones femeninas en la producción narrativa de Ricardo Piglia}

Los textos literarios del siglo xIX se sustentaban en simples oposiciones binarias del tipo hombre-mujer, auspiciadas por la jerarquización patriarcal que somete toda la organización conceptual del mundo al hombre. De este modo, el hombre se (auto)construye como un sujeto privilegiado, un sujeto activo frente a la pasividad femenina a la que le es negada la agencia. Como explica María Antonieta Pereira, a finales del $\mathrm{xx}$, la virtualidad de lo real y la inestabilidad de las verdades científicas impusieron una nueva lectura del mundo. Esta nueva lectura estaría marcada por la heterogeneidad, multivalencia y performatividad del sujeto frente a la dualidad esencialista del siglo pasado: el sexo, la raza o cualquier otro objeto en estado puro ya no existe; todo es mezcla permanente: «Así, determinados elementos del texto literario o social que permanecieron invisibles a las lecturas de épocas anteriores son resaltados dentro de la red de significaciones de la actualidad y propician otras producciones de sentido» (80).

Si a lo largo de la historia todas las oposiciones binarias han estado supeditadas por la observación del sujeto masculino, Hélène Cixous propone como defensa la puesta en duda de esta solidaridad entre el logocentrismo y el falocentrismo "para amenazar la estabilidad del edificio masculino que se hacía pasar por eterno-natural: haciendo surgir, en lo que se refiere a la feminidad, reflexiones, hipótesis necesariamente ruinosas para el bastión que aún detenta la autoridad» (16). Pero, ¿cómo hacer surgir a la mujer y formular una nueva lectura del mundo? Apunta Francine Masiello que la mujer, en cuanto sujeto no nombrado del debate filosófico o político - $y$ añadimos nosotras: también literario- solo puede irrumpir en el escenario público haciendo uso de la capacidad del despiste: a través del doble, de la máscara, del disfraz. De esta manera, las mujeres llegan a representar la paradoja de las tensiones existentes entre la conformidad con un sistema de valores y leyes, y un libre albedrío.

Ahora bien, y partiendo de este lugar - no lugar- que la mujer ha venido ocupando en la sociedad y en la historia de la literatura, nos proponemos en este apartado abordar el tratamiento que Ricardo Piglia hace del sujeto femenino ${ }^{3}$ en su obra:

3. Dada las limitaciones formales, en este apartado solo nos ocuparemos de analizar las figuras femeninas en algunos cuentos ¿qué papel ocupa la mujer en la narrativa del autor argentino? ¿Cómo y por quién es narrada/mirada la mujer? ¿Qué procedimientos o elementos utiliza el autor para introducirla en la narración? Desde su primera aparición en la escena literaria, en los cuentos de Jaulario - más tarde, ampliado y reeditado como La invasión - la mujer o mejor dicho, su pérdida, constituyen el motor de las narraciones de Ricardo Piglia. De hecho, y como recoge Gallego Cuiñas: «sin ella [la mujer] no hay narración, no hay texto. Lo que está ausente en lo real es lo que importa. Y lo que sobresale en lo real de los personajes de estos cuentos es la mujer: su ausencia» (154). El procedimiento de la ausencia femenina como motor del relato se observa en varios de sus primeros cuentos: «Desagravio», donde Fabricio ha sido abandonado por su mujer y desea recuperarla; en «El joyero» donde se narra la falta de la hija; en «Un pez en el hielo» $\mathrm{y}$ "El precio del amor» en los que se pierde a la mujer amada, etc. En todos estos textos se forja una visión de la mujer como objeto, como fetiche; algo que no se tiene y se desea. Siempre aparece narrada a partir de una voz enunciadora masculina, que es la que se dibuja como sujeto de la acción: el hombre siente la pérdida de la mujer y comienza la narración. La mujer no tiene voz, sin embargo, ella es la voz del texto.

En otro de los relatos de La Invasión, «Tierna es la noche», el narrador comienza a escribir a partir del suicido de la mujer protagonista, Luciana, una mujer inestable, loca, independiente. Este modelo de mujer loca también es explotado en «La loca y el crimen" y en "El fluir de la vida", como arma política en contra de la normatividad social. Sobre la voz femenina en Piglia, Orecchia Havas sostiene que cristaliza la capacidad esencial de la ficción: la invención ("Máscaras del sujeto» 248). De esta manera, como apunta también Gallego Cuiñas (2), la mujer constituye en Piglia el motor ficcional del relato, al tiempo que la locura deviene resistencia ideológica contra la norma del Estado represor y del sistema capitalista. Además, tanto en el «El fluir de la vida» como en "Matt-hari 55», asistimos a un desdoble de la voz narradora, sobre la base de un deslizamiento entre la voz masculina y femenina que presenta diferentes puntos de vista de una misma historia. Con este desdoble de la voz narradora, se articula un espacio genérico también doble: masculino y femenino

de La invasión, "Hotel Almagro» y "La mujer grabada», y de una única novela: La ciudad ausente. 
a la vez, con lo cual el narrador pasa a convertirse en un personaje andrógino. Explica Ocrecchia Havas:

$\mathrm{Al}$ incluir [...] a la voz femenina en el origen de la enunciación narrativa, el texto hace de esta última un objeto cuyo otro femenino representa la energía de la creación ficcional en estado puro. El narrador es quien, al intentar apresar la verdad (de la ficción o del recuerdo), solo trabajaría por analogía con respecto a esa voz misteriosa que se desprende de un cuerpo de mujer («Máscaras del sujeto» 250).

El mismo tema del doble reaparece en dos textos más tardíos de nuestro autor: "Hotel Almagro» y «La mujer grabada». En "Hotel Almagro» se narra un misterioso intercambio epistolar entre una mujer $\mathrm{y}$ un hombre que es interrumpido por la separación y la locura. Asistimos pues a una fragmentación de vidas, de espacios, de tiempos, pero principalmente a una fragmentación simbólica de sujeto y género, que representa tanto a la mujer — siempre caracterizada por la sinrazón, el encierro y la enfermedadcomo al hombre. Este sujeto escindido aparece la mayor parte de las veces como un sujeto indefinido; no sabemos quién narra, lo cual nos muestra la confusión de identidades y la ambivalencia del sujeto (Orechia ctd. en Mesa Gancedo 255), también en contra — como sucedía con la locura- de la normatividad social (y literaria).

Por otro lado, en «La mujer grabada» se aborda a la mujer de una forma muy similar a la de La ciudad ausente, que relaciona a un sujeto femenino no cuerdo, loco, con el escritor, que sería su padreamante simbólico. Sobre el personaje femenino de este cuento, apunta Teresa Orecchia Havas: «la mujer del grabador, personaje de vagabunda delirante enraizado en una geografía porteña que tiene puntos en común con las narraciones de los años sesenta y setenta, pero también con la ciudad enigmática de la segunda novela, parece un resumen de los tópico que afectan al personaje femenino» ("Máscaras del sujeto» 256). Recordemos que el personaje femenino de este texto, Rosa, porta consigo un grabador que recoge dos voces diferentes. Este grabador, señala Orecchia Havas, sería el análogo a las cartas de "Hotel Almagro», toda vez que se puede leer como una variante de la caja de cristal en La caja de vidrio, o como la máquina de la literatura en $L a$ ciudad ausente. Esa grabadora contenedora de dos voces «remite a la escisión y a la complementariedad entre los géneros (masculino/femenino) y vuelve a desarrollarse a partir de un [...] diálogo entre un hombre y una mujer» («Máscaras del sujeto» 256). A la vista de lo expuesto, podemos determinar que el sujeto femenino en estos textos de Ricardo Piglia, que justamente han sido los más estudiados por la crítica, ocupa el lugar de la indeterminación. A través de la disyuntiva hombre-mujer — nunca clara- el autor construye un narrador andrógino que implica una equiparación entre los sujetos, acabando con cualquier tipo de desigualdad (política, social o literaria) o preponderancia de género.

Pero también encontramos otro tema en la producción pigliana que vincula al sujeto femenino con el tema del doble, e incluso con el tema de la locura: la mujer como monstruo (Haraway). Si pensamos en las representaciones literarias de la mujer como sujeto en la historia literaria comprobamos que ha sido tradicionalmente asociada a lo monstruoso. Señala López-Labourdette que lo monstruoso supone un retorno al cuerpo, lo que explicaría que con frecuencia la mujer haya sido reducida a pura biología. Un ejemplo de esto podrían ser las Medusas, las Amazonas, las Arpías, las Sirenas; todas ellas personajes definidos por su excentricidad física, que encarnan la metáfora de la mujer como maldad. Sobre ese cuerpo deforme de la mujer-monstruo se ha inscrito no solo la maldad sino la amoralidad, y aquí radica el problema, pues como sostiene López-Labourdette:

La deformidad en sí no encarna violencia si no es frente a la misma norma, mucho menos violación moral. Así lo demuestra la idea de lo monstruoso como prodigio. Asimismo, la poblada comunidad de deidades monstruosas de la Antigüedad, para la que la transformación genérica y la conectividad de las especies constituyen una de las cualidades de lo divino, pone en evidencia la condición cultural de la carga negativa asociada al monstruo (153).

Esta carga negativa con la que se relaciona al monstruo tendría su explicación en un sistema de pensamiento binario, al que aludimos al comienzo de este epígrafe, dominado por una metafísica de la esencia y un sistema de la diferencia - la femenina, pero también cualquier otra- como Otro de lo Mismo, es decir: como Otro devaluado y frágil. La pregunta entonces se precipita: ¿podemos entender el vínculo de la mujer con el monstruo como una suerte de legitimación de las formas impuestas por el sistema falogocéntrico? López-Labourdette indica que la equiparación mujer-monstruo refuerza por un lado, la postura patriarcal pero por otro, afirma el inmenso poder de la mujer. Por tanto, en esta 
paradoja y ambivalencia de la mujer como monstruo, podemos observar diferentes tratamientos del sujeto femenino en la literatura. En este rubro, entraría parte de la narrativa de Piglia, donde la mujer es muchas veces una encarnación de lo raro y de lo monstruoso, pero: ¿qué connotaciones le da el autor argentino a la mujer-monstruo? ¿Qué trata de representar a través de esa anomalía?

Para responder a esta pregunta, vamos a centrarnos en el texto pigliano más importante para el análisis del tratamiento del sujeto femenino en su obra: La ciudad ausente (1992), donde aparece muy trabajada — como ya hemos adelantado- la mujer en relación con el tema del doble. El monstruo-narrador de esta obra cuenta las historias desde un punto de vista masculino, pero a su vez se desdobla en otros personajes femeninos que van narrando otras historias (Pereira 81). Lo que en el siglo XIX hubiesen sido dos categorías claramente identificables se unen un siglo más tarde en una mezcla heterogénea, en una especie de narrador andrógino que se escapa de la normatividad. Por eso, enuncia Orecchia Havas, a partir de La ciudad ausente - y como hemos visto en otros textos previos- "se construye un mito de la creación literaria centrado en torno a la emergencia de una voz femenina, que sería la propia voz de la literatura» ("Máscaras del sujeto» 239). Esta voz femenina que se genera en La ciudad ausente a través de la máquina de narrar aludiría así a una figuración femenina rebelde y subversiva. Esto es: antinormativa.

Según lo argumentado hasta ahora, y haciendo una elipsis de parte de la producción pigliana para focalizar solo en los textos donde la figura de la mujer cobra relevancia, podemos notar grandes diferencias entre los primeros cuentos de La invasión, en los que el sujeto femenino aparecía como resto o residuo del orden simbólico definido por el orden patriarcal (Orecchia Havas, "Género y metaforización» 2) y las obras que le siguieron, donde las fronteras entre lo masculino y lo femenino se desdibujan y confunden, permitiendo nuevas formas, ambivalentes, performáticas (Butler) de narrar/mirar la mujer. La idea de la mujer como lo otro, como lo raro y como lo monstruoso refuerza la capacidad narrativa del sujeto femenino en la literatura de Piglia. De ahí que en sus últimos textos ya no se conciba a la mujer como objeto pasivo de deseo generado por la ausencia, sino que pase a formar parte activa de la narración y sea incluso, en muchos casos, agente narrador junto con la figura masculina. Con ello afirmamos que las figuras femeninas en la obra de Ricardo Piglia, a partir de los noventa, son representadas por el devenir, lo performático e incluso lo monstruoso, amén de construir(se) como sujetos con agencia, con un espacio y con un poder narrativo propio en el texto.

\section{La mujer en la novela de campus: El camino de Ida de Ricardo Piglia}

A la luz de este recorrido por las representaciones del sujeto femenino en la narrativa de Ricardo Piglia, abordaremos su última novela: El camino de Ida (2013). En este relato, el profesor argentino Emilio Renzi es invitado por una prestigiosa universidad de New Jersey para dictar un seminario sobre los años argentinos de W. H. Hudson. Renzi, abrumado y cansado de su vida en Buenos Aires, acepta la invitación de Ida Brown, una estrella del mundo académico, con la idea de dar un giro a su vida. El argentino ve en el cambio de aires una nueva oportunidad para encontrar sentido a su vida. Sin embargo, su plan se transforma nada más llegar al campus. Comienza a mantener una relación clandestina basada en una serie de encuentros fortuitos - con la profesora Ida Brown, quién poco después aparece muerta en su coche. Cuando la encuentran, tiene la mano quemada, hecho que la relaciona con una serie de asesinatos que se están cometiendo desde hace tiempo contra eminentes figuras del mundo académico.

Como consecuencia - $-\mathrm{y}$ debido a la penosa investigación realizada por el FBI-, Emilio Renzi contrata a un detective, Ralph Parker, para que le ayude a conocer la verdad sobre la misteriosa muerte de su compañera. En la búsqueda de pistas, Renzi se enfrentará a una combinación de enigmas que confluirán en la articulación de respuestas - y problemáticas - de índole académico, social y político. El papel de la literatura, y su función social, - y principalmente la obra The secret agent de Joshep Conradtiene un peso muy importante en la novela, pues será a través de la ficción y de sus conexiones con la política y con la vida que finalmente se podrán desentrańar (casi) todos los interrogantes de la muerte de Ida, los cuales acabarán apuntando a la culpabilidad de Thomas Munk ${ }^{4}$, un brillante matemático de

4. A la hora de configurar el personaje de Thomas Munk, Piglia se ha inspirado en Theodore Kaczynski, más conocido como Unabomber: un matemático anarquista, antisistema y antinormativo que se dedicó a enviar cartas-bombas entre 1978 
la Universidad de Berkeley, que decide retirarse de la vida académica y tramar una red conspirativa contra el Estado y sus secuaces.

En este policial académico, el campus universitario aparece retratado como un arma de doble filo. Por un lado, es un lugar de «violencia psíquica» por donde circulan «altas olas de cólera subterránea: la terrible violencia de los hombres educados» (Piglia 35 ), toda vez que aparece como uno de los hacedores del pensamiento normativo (por eso Munk ataca a universitarios). Pero por otro lado, también se erige como el lugar que ha permitido a los protagonistas, Ida Brown y Thomas Munk, configurarse como sujetos activos con un gran capital simbólico a ojos de la sociedad, que a su vez les permitirá atentar contra el modelo económico (capitalista) dominante. La universidad entonces se muestra simultáneamente como espacio de violencia y como espacio productor de saber (alternativo) y acción (política).

Si retomamos el enfoque femenino en la obra de Ricardo Piglia, encontramos que, aparentemente, en esta novela se reproduce la imagen de la primera narrativa de Piglia, donde la pérdida de la mujer es el motor que impulsa la narración de la historia. De igual forma, El camino de Ida sigue ese recorrido y parte de ese mismo supuesto: la muerte de Ida Brown en unas circunstancias misteriosas, que funciona como impulso para la narración/investigación. Asimismo, la obsesión que despierta el narrador por la muerte de Ida está estrechamente vinculada con la obsesión que ella despierta en Renzi. A este respecto, compartimos la idea de Baudrillard (ctd. en Pereira 122) de que «la seducción constituye el eclipse de la presencia. La única estrategia es estar/no estar allí y así garantizar una presencia de intermitencia, de dispositivo hipnótico que cristaliza la atención fuera de cualquier efecto de sentido. La ausencia seduce a la presencia». De ahí que, como matiza Pereira, «la presencia de la mujer, eclipsada por la muerte, la convierte en un deseo que provoca la escritura» (123). Pero en El camino de Ida el sujeto femenino es más complejo, y la mujer, además de objeto de deseo es también sujeto de la narración, del pensamiento. ¿Y quién, como sujeto, es Ida Brown?

Ida era una estrella del mundo académico, su tesis sobre Dickens había paralizado los estudios sobre el autor de Oliver Twist por veinte años. Su sueldo era

y 1995 a una serie de intelectuales universitarios a modo de crítica contra el desarrollo de la sociedad contemporánea. un secreto de Estado, decían que se lo aumentaban cada seis meses y que la única condición era que debía recibir cien dólares más que el varón (ella los llamaba así) mejor pagado de su profesión. Vivía sola, nunca se había casado, no quería tener hijos, estaba siempre rodeada de estudiantes, a cualquier hora de la noche era posible ver la luz de su oficina encendida e imaginar el suave rumor de su computadora donde elabora tesis explosivas sobre política y cultura. También era posible imaginar su risita divertida al pensar en el escándalo que sus hipótesis iban a causar entre los colegas. Decían que era una esnob [...], pero todos envidiaban su inteligencia y su eficacia (18-19).

Ida Brown es presentada por el narrador de Piglia como una profesora especialista en Joseph Conrad "que se había casado con la Academia como las monjas de clausura se desposaban con Jesucristo» (61). Se trata de una intelectual, feminista, que se ha construido como una figura dura y problemática por muchas de la hipótesis y supuestos que ha propuesto frente a sus colegas académicos (varones: no olvidemos que la academia es una institución patriarcal). $Y$ es este saber universitario, el capital simbólico que ha adquirido en la academia, el que posibilita que se haya consagrado como una experta en J. Conrad y por tanto, que se convierta en una agente reveladora de su obra. Es ella quien deja el ejemplar de The Secret Agent con su propia lectura sobre el texto a Renzi y son estas anotaciones y marcas, que realiza el sujeto femenino Ida, las que conducirán a que el narrador masculino establezca los puntos de conexión entre la literatura y la política; entre Munk y los atentados, entre Ida y Munk. No es el propio texto en sí el que funciona como revelador del enigma sino que sería la traducción que de él realiza Ida la que suministra la clave de lectura/interpretación: el sentido. Esto es: Ida lee a Conrad, lo traduce y deja anotada su traducción — su lectura, sus marcas - en el libro a través del cual señala el camino que hay que seguir para la resolución del enigma que está detrás de los atentados contra la academia. El mismo narrador señala esta labor reveladora de Ida: «ella tejía, con sus señas, un relato secreto, en voz baja, pequeńos indicios [...] Los fragmentos desarticulados que Ida iba enlazando en la novela formaban un tejido que dejaban ver - a trasluz - la figura de Munk» (226-229).

A través de esta cita, Ida se nos presenta como una fuente de conocimiento. La mujer como sujeto activo que conoce, piensa (porque sabe leer), comparte y lega ese saber. Así, se desplaza el sujeto 
femenino del deseo a la acción. Ida Brown no deja de manera fortuita el texto de Conrad a Renzi sino que ella es quien lo elige como depositario de su saber. Por tanto, Ida no solo constituye una obsesión del narrador, sino que además supone su fuente de conocimiento. Renzi conoce, aprende a leer, a descifrar, gracias a Ida. La ausencia del sujeto femenino es lo que moviliza al narrador en un primer momento, pero a su vez, serán las lecturas y escrituras de Ida, su pensamiento, lo que propicie el avance del relato y el esclarecimiento final.

Ahora bien, las anotaciones de Ida en la obra de Conrad pueden significar dos cosas: o bien que ella descubrió en la novela el plan de Thomas Munk y dejó la obra anotada a Renzi porque quería que esto fuera revelado; o bien que ella ha sido la artífice teórica o cómplice del plan que Munk ha llevado a cabo. Ella, experta conocedora de la obra de Conrad, y unida a Munk por una relación del pasado, podría haberle proporcionado a este la novela que ejemplifica su ideario y la perpetración de sus acciones. Así lo manifiesta nuestro narrador, que se decanta por la segunda hipótesis, a través de varias suposiciones que desarrolla a lo largo de la novela:

No creían que el caso de Ida perteneciera a esa serie aunque su muerte era dudosa. Salvo, agregó, que ella formara parte del grupo y hubiera muerto al activar una bomba que pensaba utilizar (o transportar) (125).

O tal vez ella colaboraba con él. Le gustaba más esa idea: la chica de armas tomar. [...] ¿Quién había influido a quién? ¿Él le había dado a ella la radicalidad de su pensamiento, esa capacidad para avanzar más allá de los límites? ¿ O había sido ella quien lo había llevado del ambientalismo abstracto y el ecologismo idiota a la violencia revolucionaria? (257).

Asimismo, en la conversación que Emilio Renzi y Thomas Munk mantienen en la cárcel también esta hipótesis es evidenciada por ambos:

- Ella era una intelectual destacada y es posible que hubiera encarada una lucha secreta en defensa de sus principios y sus ideales. No importa si estaba equivocada o tenía razón, pero murió por algo en lo que ella creía y eso daba sentido a su muerte...

- Ida fue una mujer valiente. Nosotros la tenemos en cuenta.

- ¿Nosotros?

— Usted y yo. Con eso basta para recordarla (283).
En rigor, desde un primer momento asistimos en la novela a la construcción de la idea de complot que conecta a Ida Brown y a Thomas Munk. Ya en el primer capítulo podemos leer: «Ida estaba interesada en la tradición de los que se oponían al capitalismo desde una posición arcaica y preindustrial. Los populistas rusos, la beat generation, los hippies y ahora los ecologistas habían retomado el mito de la huida natural y la comuna campesina» (20). Esto es precisamente lo que encarna la figura de Joseph Conrad, cuyo núcleo central de su obra era "la decisión de cambiar de vida» (233). Y a esto mismo es a lo que se abocan Ida Brown y Thomas Munk, personajes que se conectan a través de la academia; a través de la literatura y de la política. Por tanto, el saber académico se configura en el texto como germen para llevar a cabo la acción política — antinormativacontra ese mismo saber universitario, según se extrae del Manifiesto de Munk «eran los científicos los que en nombre del progreso tecnológico legitimaban la violencia del sistema, los experimentos biológicos y los bélicos. Eran esos "técnicos del saber práctico" los que violentaban la ética en nombre del progreso y de la ciencia» (164).

Asimismo, si apostamos por la hipótesis que conecta a Ida con los atentados y con Thomas Munk, habría sido ella también quien habría legado a Munk la obra que describía las acciones que este debía llevar a cabo. En realidad, lo que Piglia está haciendo a

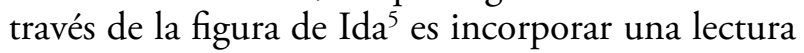
feminista al personaje antisistema de Unabomber, considerado como anarquista y ecologista. La hipótesis de Piglia habría de ser que, de alguna manera, para ser totalmente antisistema se necesita también ser feminista. Unabomber, sin feminismo, no sería completamente antinormativo. Por eso el argentino le da, en esta ficción, a Unabomber lo que la falta: una cómplice, una mujer, un punto de vista feminista.

La hipótesis de Ida como cómplice o artífice de las acciones de Munk se reafirma si tenemos en cuenta la construcción dual que Piglia inventa para sus personajes en El camino de Ida. Ida Brown es un personaje que construye su vida en torno a dos espacios: el espacio público/visible y el espacio privado/no visible. En el primero, se muestra como una brillante y

5. La configuración de Ida como sujeto antinormativo y combatiente conecta, a su vez, con el arquetipo de la guerrillera, estudiado por Macedo Rodríguez en la obra de Ricardo. Sin embargo, las limitaciones formales de este trabajo no nos permiten ahondar en estas relaciones que debemos dejar para trabajos futuros. 
exitosa profesora de Literatura. En el segundo, en el ámbito privado, encarna a la femme fatale, que sale en la noche a encontrarse con un semidesconocido en la curva nocturna de un parque arbolado (62). Esta dualidad se materializa en el contestador telefónico en el cual el propio personaje se presenta como un ser plural: «ahora no podemos atenderle» (84). De esta voluntad de ocultar una doble vida, deducimos la posibilidad de querer ocultar una historia que no es aparente. Así ocupar la dualidad y por tanto, un locus inesperado - ese lugar donde no se espera que estemos - vendría a mostrar a Ida como un sujeto agente. O mejor: como un sujeto con agencia. Desde este punto de vista feminista, la imprevisibilidad del sujeto femenino en la obra podría leerse, "por un lado, como una forma de resistencia a la inscripción completa y acabada según un ideal sumiso y doméstico; pero, por otro, también como ejemplo de una experiencia crítica, marginal y periférica, que rechaza el lugar de Otra exótica y emocional que se nos prescribe» (Femenías 15).

No obstante, Ida también es tildada por el narrador de sujeto raro o poco cuerdo. Es decir: de loca, como las anteriores mujeres de sus relatos. Dice Renzi sobre ella: «Su nombre era una acción, la ida, el viaje sin retorno, señala quien se va. Y también a la muchacha rara ('está ida' o es 'medio ida')» (182). Así, se establece una analogía entre Ida y Munk, quien es catalogado como psicótico cuando es reconocido como autor de los atentados. Ida encarnaría a una loca desde la teoría, a la desviada, a la que está fuera de la norma ${ }^{6}$, que a su vez se cristaliza en acción a través de la figura de Thomas Munk. Por tanto, podemos considerar a Ida Brown como un sujeto activo y agente desde esa figura ambivalente y no normativa (como mujer loca, monstruosa y diferente) que despliega en el espacio público.

De otro lado, tenemos a otra mujer, fundamental, en esta novela de campus: Nina Andropova ${ }^{7}$, la vecina de Emilio Renzi. Esta catedrática jubilada de literaturas eslavas, experta en Tolstoi, se inserta en el mundo académico estadounidense a través de la mirada extranjera, igual que Renzi. Ella, rusa exiliada

6. Leemos en El último lector: «En el exceso, algo de la verdad de la práctica de la lectura se deja ver; su revés, su zona secreta: los usos desviados, la lectura fuera de lugar» (Piglia 23).

7. Debido a las restricciones formales de este trabajo no podemos ahondar en el otro gran personaje femenino: Nina Andropova, de quien apuntaremos algunas notas generales con la perspectiva de retomarlas y ampliarlas en futuros trabajos sobre el tema. en Estados Unidos, constituye un puente entre la literatura norteamericana y la literatura rusa a través de sus reflexiones sobre el lenguaje en ambos idiomas y mediante los postulados de Tolstoi acerca de la no violencia y de la no resistencia al mal que lo unen con la ideología del criminal Thomas Munk (Fernández Cobo 647). Si además de esto tenemos en cuenta que representa, según la teoría de Piglia sobre el género policial («La ficción paranoica»), la figura del detective clásico de la novela policiaca, Nina Andropova, a quien se le dedica la segunda parte de la obra ( vecina rusa»), funciona - del mismo modo que Ida - como medio de conocimiento y revelación del enigma que se cifra en la obra. Las mejores lectoras ${ }^{8}$, las que tienen la cultura y el pensamiento, las que leen mal - de una manera desviada, al margen de la norma9 - son las mujeres en El camino de Ida. Por eso Renzi afirma que su vecina fue la primera persona en descifrar la relación entre la muerte de Ida y los atentados contra los académicos a través de la prensa:

Fue Nina quien primero conjeturó lo que realmente había pasado. Solo algunas notas aisladas en los periódicos permitían imaginar que había una sucesión de incidentes extraños entre los que podía incluirse también la muerte de Ida [...] ¿Quizá los profesores se estaban matando entre ellos?, ironizaba Nina (108).

El conocimiento que la profesora jubilada tiene de la historia, de la literatura y del sistema universitario le permite ubicar el lugar desde el que proviene el terrorista: la universidad, al tiempo que se evidencian desde las — perversas — formas de actuación de esta institución:

Nina conocía bien el mundo académico, lo consideraba una jungla más peligrosa que los pantanos de Vietnam. Gente muy inteligente y muy educada que por las noches sueña con venganzas terribles. Había pasado por todas las escalas de la así llamada carrera académica y sabía de los rencores los odios que recorría los departamentos universitarios donde los profesores conviven durante décadas (109).

8. Si Emma Bovary era una lectora ideal para Piglia, porque debe hacer lo que lee, Ida Brown es su reverso posmoderno: ella lleva la lectura, política, a una forma antisistema de vida.

9. Recordemos que en El último lector Piglia sostiene: «En la clínica del arte de leer, no siempre el que tiene mejor vista lee mejor» (19). 
Por tanto, de estas apreciaciones podemos colegir que se establece un paralelismo entre los personajes femeninos principales: Ida Brown y Nina Andropova, profesoras de literatura, expertas en la materia que ocupan un lugar reconocido y prestigioso dentro de la academia. Ambas se dibujan como intelectuales, fuente de conocimiento, motores principales de la narración:

El lector, entendido como descifrador, como intérprete, ha sido muchas veces una sinécdoque o una alegoría del intelectual. La figura del sujeto que lee forma parte de la construcción de la figura del intelectual en el sentido moderno. No sólo como letrado, sino como alguien que se enfrenta con el mundo en una relación que en principio está mediada por un tipo específico de saber. La lectura funciona como un modelo general de construcción del sentido (Piglia, El último lector 103).

En efecto, Ida y Nina, desde una posición y con unos intereses distintos, llevan a cabo una lectura aguda del sentido político, literario y social del sistema capitalista neoliberal, mediante una actividad detectivesca, de desciframiento, que hace avanzar la narración. Este conocimiento proporcionado por los agentes femeninos será el que permita a Renzi el trazado del mapa que ha de seguir para llegar hasta Munk. Por lo tanto, observamos cómo en El camino de Ida las figuras femeninas son delineadas como sujetos activos, constructores del conocimiento y del sentido, intelectuales - no varones - con una voz propia que se presenta como la palabra (la lectura, la escritura) necesaria para llegar al fin de la investigación. Así, con estas mujeres Piglia logra resolver en su última novela esa tensión entre el acto de la lectura y la acción política, la experiencia (El último lector 103).

Se trenzan entonces en El camino de Ida los dos perfiles narrativos de los sujetos femeninos en la obra de Ricardo Piglia: por un lado, Ida se pueda equiparar con los sujetos que encontrábamos en los textos de La invasión, pero a medida que se desarrolla la trama, ella, junto con Nina, se postulan como sujetos activos del relato que toman la (última) palabra, como últimas lectoras. Ambas ocupan un lugar coprotagónico con Renzi y Thomas Munk, que habrían de ser subsidiarios del pensamiento femenino/feminista, ya que estas mujeres son las que les proporcionan la información y los datos a los dos sujetos masculinos para que la investigación/narración avance. Entonces, estas representaciones femeninas se equiparan con la literatura, pero a partir de su presencia - que no de su ausencia - en el relato, convirtiéndose no solo en motores de la narración sino de la investigación (el pensamiento). Es el ser, el saber y el estar del sujeto femenino lo que hace que la narración se abra camino, operación insólita en las obras anteriores del autor argentino.

Del mismo modo, este saber femenino quedaría inserto en el saber universitario, puesto que es en la experiencia de la lectura que da la academia, en el saber, que Ida Brown y Thomas Munk encuentran un arma para atacar el sistema capitalista. Por lo tanto, el campus universitario y la figura de la mujer intelectual son los que posibilitan que leamos $E l$ camino de Ida no solo como una novela de campus al uso, con el género policial de fondo, sino como un texto feminista contra la normatividad neoliberal y su violencia atroz. Es decir: como una de las primeras novelas de campus feministas de América Latina.

\section{Bibliografía}

Butler, Judith. El género en disputa. México: Paidós, 2001.

Carrión, Jorge. El lugar de Piglia: Critica sin ficción, Barcelona: Candaya, 2008.

Castagnino, María Inés. «Novela académica: reflexiones sobre sus orígenes en Inglaterra y Estados Unidos». Memoria académica. Facultad de Humanidades y Ciencias de la Educación de la Universidad Nacional de La Plata. <http://www.memoria.fahce.unlp.edu.ar/ trab_eventos/ev.2402/ev.2402.pdf>. Consultado el 11 de Enero de 2019.

Cixous, Hélène. La risa de la medusa: Ensayos sobre la escritura. Trad. Myriam Díaz-Diocaretz. Barcelona: Antrophos, 1995.

DAwEs, G. «Hacia el pasado para llegar al futuro: $E l$ camino de Ida, de Ricardo Piglia». Gramma, 28:58, (2017).

Femenías, María Luisa. «Esbozo de un feminismo latinoamericano». Revista Estudos Feministas, 15: 001, (2007): 11-25.

Fernández Coвo, Raquel. «La cólera subterránea o la terrible violencia de los hombres educados: formas de la violencia en El camino de Ida de Ricardo Piglia». Álvarez López, José Luis et al (ed.). Tuércele el cuello al cisne: las expresiones de la violencia en la literatura hispánica contemporánea (siglos XX y XXI). Sevilla: Renacimiento, 2016, 641-655. 
Fornet, Jorge. El escritor y la tradición. Ricardo Piglia y la literatura argentina. Buenos Aires: Fondo de Cultura Económica, 2007.

Gallego Cuiñas, Ana. «La ficción paranoica de Ricardo Piglia en "Un pez en el hielo": encrucijada narrativa». Otro lunes. Revista Hispanoamericana de Cultura. 2007.

García Del Río, Antonio. «Clandestinidad y periferia. Usos del genero policial en la narrativa de Ricardo Piglia». Kamchatka. 2015. <https://ojs.uv.es/index.

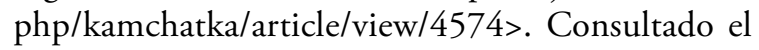
20 de En. de 2019.

GarCía Rodríguez, Javier. «Apuntes para la caracterización de la literatura de campus con un muestrario (necesariamente) incompleto de obras». Clarín. Revista de Nueva Literatura, 37, (2002): 3-13.

García Rodríguez, Javier. "Escribe cien veces: "no me reiré de los profesores". (Humor, sátira académica y novela de campus reciente en Espańa)». Pasavento. Revista de Estudios Hispánicos, 3:2 (2015): 273-293.

Gil-Albarellos, Susana. «La novela de campus en España 2000-2015». Cuadernos de Investigación Filológica, 43 (2017): 191-207.

HaraWaY, Donna. «Las promesas de los monstruos: Una política regeneradora para otros inapropiados/bles». Elena Casado (trad.). Revista Politica y Sociedad: 30, (1999).

Lafforgue, Jorge. Cuentos Policiales Argentinos, Buenos Aires: Aguilar / Altea / Taurus/ Alfaguara, 1997, 9-22.

López-Labourdette, Adriana. «¿Devenir mujer, devenir monstruo? Cuerpos y textos monstruosos Carmen Boullosa y Guadalupe Nettel». Claudia Gronemann I Cornelia Sieber (ed.), Fiestas infinitas de la máscara: Actos performativos de feminidad y masculinidad en México, Hildesheim: Olms, 2012, 149-168.

Macedo Rodríguez, Alfonso. "Los guerrilleros en la narrativa de Juan José Saer y Ricardo Piglia». Latinoamérica. Revista de Estudios Latinoamericanos, 67 (2018): 239-265.

MaLtz, Hernández. «Narrativa policial y academia en la Argentina. Dos recapitulaciones en torno a una convergencia: el policial académico», Hápax, 11, (2018): 117-142.

Masiello, Francine. Entre civilización y barbarie. Mujeres, nación y cultura. Buenos Aires: Beatriz Vitiebo Editora, 1997.
Mesa Gancedo, Daniel (Coord.). Ricardo Piglia. La escritura y el arte nuevo de la sospecha. Sevilla: Universidad de Sevilla, 2006.

Moore-Martínez, Patricia. The Emergence of the Spanish Peninsular Campus Novel. Philadelphia: Temple University, 2009.

Newman, Kathleen Elizabeth. La violencia del discurso. El Estado autoritario y la novela políticaargentina. Buenos Aires: Catálogos Editora, 1991, 95-114.

Orecchia Havas, Teresa. «Máscaras del sujeto y mitos de origen del relato en la narrativa de Ricardo Piglia». Daniel Mesa Gancedo (coord.) Ricardo Piglia. La escritura y el arte nuevo de la sospecha, Sevilla: Universidad de Sevilla, 2006, 239-261.

Orecchia Havas, Teresa. «Género y metaforización de la creación literaria en dos obras de Ricardo Piglia». Orbis Tertius, 15 (16), 2010. <http://www.guntesmemoria. fahce.unlp.edu.ar/art_revistas/pr.4242/pr.4242.pdf.> Consultado 10 de Enero de 2019.

Pereira, Maria Antonieta. Ricardo Piglia y sus precursores, Buenos Aires: Corregidor, 2001.

Piglia, Ricardo. La invasión. Barcelona: Anagrama, 1967.

Piglia, Ricardo. La ciudad ausente. Buenos Aires: Sudamericana, 1992.

Piglia, Ricardo. «La loca y el relato del crimen». Cuentos morales. Buenos Aires: Planeta bolsillo, 1997, 89-98.

Piglia, Ricardo. El último lector. Barcelona: Anagrama, 2005.

Piglia, Ricardo. "La ficción paranoica». Ezequiel De Rosso (coord.). Retóricas del crimen. Reflexiones latinoamericanas sobre el género policial, Jaén: Alcalá Grupo Editorial, 2011: 225-233.

Piglia, Ricardo. El camino de Ida. Barcelona: Anagrama, 2013.

Reati, Fernando y Gómez Ocampo, Gilberto. «Académicos y gringos malos: la universidad norteamericana y la barbarie cultural en la novela latinoamericana recinete». Revista Iberoamericana, 64, (1998): 587-609.

Sasturain, Juan, "Hammett, el amigo americano». Roman Setton y Gerardo Pingnatiello (comps.), Crimen y pesquisa. El género policial en la Argentina (1870-2015): literatura, cine, televisión, historieta y testimonio, Buenos Aires: Título, (2016), 35-42.

Villamía, Luis. «El despliegue de la autoficción en la academia: La novela de campus en la narrativa actual». Pasavento. Revista de Estudios Hispánicos, 3:1, (2015): 43-55. 